\title{
The Mycobacterium tuberculosis Uganda II family and resistance to first-line anti-tuberculosis drugs in Uganda
}

Nicholas Ezati ${ }^{1 \dagger}$, Deus Lukoye ${ }^{1 \dagger}$, Eddie M Wampande ${ }^{3,5}$, Kenneth Musisi ${ }^{2}$, George W Kasule ${ }^{2}$, Frank GJ Cobelens ${ }^{4}$, David P Kateete ${ }^{3}$ and Moses L Joloba ${ }^{2,3^{*}}$

\begin{abstract}
Background: The global increase in the burden of multidrug-resistant tuberculosis (MDR-TB) underscores an urgent need for data on factors involved in generation and spread of TB drug resistance. We performed molecular analyses on a representative sample of Mycobacterium tuberculosis (MTB) isolates. Basing on findings of the molecular epidemiological study in Kampala, we hypothesized that the predominant MTB strain lineage in Uganda is negatively associated with anti-TB drug resistance and we set out to test this hypothesis.

Methods: We extracted DNA from mycobacterial isolates collected from smear-positive TB patients in the national TB drug resistance survey and carried out IS6110-PCR. To identify MTB lineages/sub lineages RT-PCR SNP was performed using specific primers and hybridization probes and the 'melting curve' analysis was done to distinguish the Uganda II family from other MTB families. The primary outcome was the distribution of the Uganda II family and its associations with anti-TB drug resistance and HIV infection.

Results: Out of the 1537 patients enrolled, MTB isolates for 1001 patients were available for SNP analysis for identification of Uganda II family, of which 973 (97\%) had conclusive RT-PCR results. Of these 422 (43.4\%) were of the Uganda II family, mostly distributed in the south west zone (55.0\%; OR = 4.6 for comparison with other zones; $95 \% \mathrm{Cl}$ 2.83-7.57; $\mathrm{p}<0.001$ ) but occurred in each of the other seven geographic zones at varying levels. Compared to the Uganda II family, other genotypes as a group were more likely to be resistant to any anti-TB drug $\left(\mathrm{OR}^{\mathrm{adj}}=2.9 ; 95 \% \mathrm{Cl}\right.$ 1.63-5.06; $p=0.001$ ) or MDR ( $\mathrm{OR}^{\text {adj }} 4.9 ; 95 \% \mathrm{Cl}, 1.15-20.60 ; \mathrm{p}=0.032$ ), even after adjusting for geographic zone, patient category, sex, residence and HIV status. It was commonest in the 25-34 year age group 159/330 (48.2\%). No association was observed between Uganda II family and HIV infection.
\end{abstract}

Conclusion: The Uganda II family is a major cause of morbidity due to TB in all NTLP zones in Uganda. It is less likely to be resistant to anti-TB drugs than other MTB strain lineages.

\section{Background}

Tuberculosis (TB) remains one of the major causes of morbidity and mortality, estimated to affect a third of the population worldwide. Through the past two to three decades TB incidence and mortality have markedly increased as a result of HIV [1], and an estimated half million multidrug resistant (MDR) TB cases exist across

\footnotetext{
* Correspondence: mlj10@case.edu

${ }^{\dagger}$ Equal contributors

${ }^{2}$ National Tuberculosis Reference Laboratory (NTRL), Kampala, Uganda ${ }^{3}$ Department of Medical Microbiology, Makerere University College of Health Sciences, Kampala, Uganda

Full list of author information is available at the end of the article
}

the world. The association between MDR-TB and HIV infection in sub-Saharan Africa (SSA) remains a controversial subject with no association documented in most settings [2-5], although some studies continue to report an association between these two disease epidemics at individual level [6-9]. The increasing global burden of MDR-TB underscores the urgent need for pathogen and host data on factors involved in generation and spread of drug resistant strains, so as to facilitate focussed interventions by the national programs for its control [10], especially in low resource and high burden TB, HIV and TB/HIV co-infection settings such as SSA.

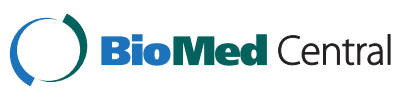

(c) 2014 Ezati et al.; licensee BioMed Central. This is an Open Access article distributed under the terms of the Creative Commons Attribution License (http://creativecommons.org/licenses/by/4.0), which permits unrestricted use, distribution, and reproduction in any medium, provided the original work is properly credited. The Creative Commons Public Domain Dedication waiver (http://creativecommons.org/publicdomain/zero/1.0/) applies to the data made available in this article, unless otherwise stated. 
Uganda is still counted among the 22 high TB burden countries worldwide with an estimated 293 per 100,000 incident cases of all TB forms in 2010 [11]. It has a high HIV prevalence, currently estimated at $7.3 \%$ among the 15-49 years age group in the general population (AIS 2011 ), with a TB/HIV co-infection rate of $54 \%$ in the 2010 TB cohort [11]. Results from the national drug resistance survey show the prevalence of MDR-TB to be low; $2.3 \%$ among sputum smear-positive new and previously treated TB patients combined [5].

Molecular epidemiological studies are useful for understanding key aspects of TB control including transmission, potential to cause disease outbreaks, and resistance to anti-TB drugs $[8,12,13]$, among others. Molecular techniques commonly used in these studies $[14,15]$ include spacer oligonucleotide typing (spoligotyping), region of difference (RD) analysis, mycobacteria insertion repetitive units (MIRU) analysis, insertion sequence 6110 (IS6110) restriction fragment length polymorphism (RFLP) [13,14], single nucleotide polymorphisms (SNP) and whole genome sequencing now the gold standard. Among these, SNPs represent reliable markers for lineage classification of Mycobacterium tuberculosis complex [16,17].

The Uganda II genotype is a sub lineage of the MTB lineage 4, the Euro- American lineage which is defined by RD 724 deletion [18]. By spoligotyping, it is defined by deletion of spacer 33-36 and spacer 40 [19]. Using the highly sensitive and specific SNP technique, the Uganda family is further subdivided into the Uganda I and Uganda II subtypes which contribute $15 \%$ and $85 \%$ respectively to this family in Uganda, although these studies were limited with respect to geographical coverage [20,21]. Earlier studies have identified the T2 family in general as an important MTB genotype in specific localities in Uganda $[19,20]$ and shown a negative association with drug resistance in a limited geographic setting [22]. This finding is potentially relevant for understanding the role of genotype diversity in the epidemiology of TB drug resistance in Uganda and elsewhere in East Africa, but calls for confirmation in a geographically more diverse dataset, among others to establish whether unrelated regional differences in genotype distribution could confound this association. Our hypothesis in this study therefore was that the Uganda II MTB subtype is the major cause of morbidity due to tuberculosis in Uganda and is negatively associated with anti-TB drug resistance, and we aimed at testing this hypothesis in a larger and geographically representative data set.

\section{Methods}

\section{Sampling and sample size estimation}

The study included new and previously treated sputum smear-positive TB patients enrolled in a national anti-TB drug resistance survey from all the NTLP zones excluding the Central Zone (see Figure 1). This was a cross-sectional survey that included 44 TB diagnostic and treatment units across the nine TB control zones (DTUs) in the country (Figure 1). A cluster sampling method was used in which 30 clusters (primary sampling units) were selected randomly with probability proportional to the number of smearpositive TB patients registered in 2007. Within each cluster a fixed number of consecutively diagnosed smear-positive patients were enrolled so that all included patients had identical sampling probabilities. Each cluster was required to enrol 50 new sputum smear-positive TB patients (for a target sample size of 1500 patients) within one year, plus all the previously treated patients diagnosed during this period.

\section{Laboratory methods Sputum collection}

Each eligible patient who consented provided two sputum samples, an early morning and a spot sample, independent of the routine samples used for diagnostic purposes to minimize chances of contamination. Samples were refrigerated at $4^{\circ} \mathrm{C}$ and then transported to the National TB Reference Laboratory (NTRL) for processing via a local courier system.

\section{Sputum culture and drug susceptibility testing}

At the NTRL, samples were decontaminated using the $1.5 \% \mathrm{NaOH}$ NALC method and processed. The sample was inoculated on two slopes of Löwenstein-Jensen (L-J) medium, incubated at a temperature of $37^{\circ} \mathrm{C}$ and monitored weekly for growth up to 8 weeks. A culture was only reported negative if no growth was shown after 8 weeks. For the positive cultures identification of MTB was done based on presumptive phenotypic appearance of colonies on the medium, and confirmed using insertion sequence 6110-based PCR method as previously described [23].

Isolates were tested for resistance to rifampicin, isoniazid ethambutol and streptomycin using the L-J proportional method, in concentrations of $40 \mu \mathrm{g} / \mathrm{ml}$ for rifampicin, $0.2 \mu \mathrm{g} / \mathrm{ml}$ for isoniazid, $2.0 \mu \mathrm{g} / \mathrm{ml}$ for ethambutol and $4.0 \mu \mathrm{g} / \mathrm{ml}$ for streptomycin, and all identified MDR-TB isolates were tested for resistance to kanamycin and ofloxacin in concentrations of $30 \mu \mathrm{g} / \mathrm{ml}$ and $2.0 \mu \mathrm{g} /$ $\mathrm{ml}$, respectively, using the method as previously described [24]. All samples resistant to rifampicin, a random sample of 20 isolates from previously treated patients susceptible to isoniazid and rifampicin, and a random sample of isoniazid resistant isolates that were susceptible to isoniazid were retested by the supranational reference laboratory in Borstel (Germany) for external quality assurance.

\section{Preparation of crude genomic DNA from Mycobacterium tuberculosis for use as template in PCRs}

A total of 1039 isolates were stored in replicates at the (NTRL) at $-80^{\circ} \mathrm{C}$. To extract DNA, the selected isolates 


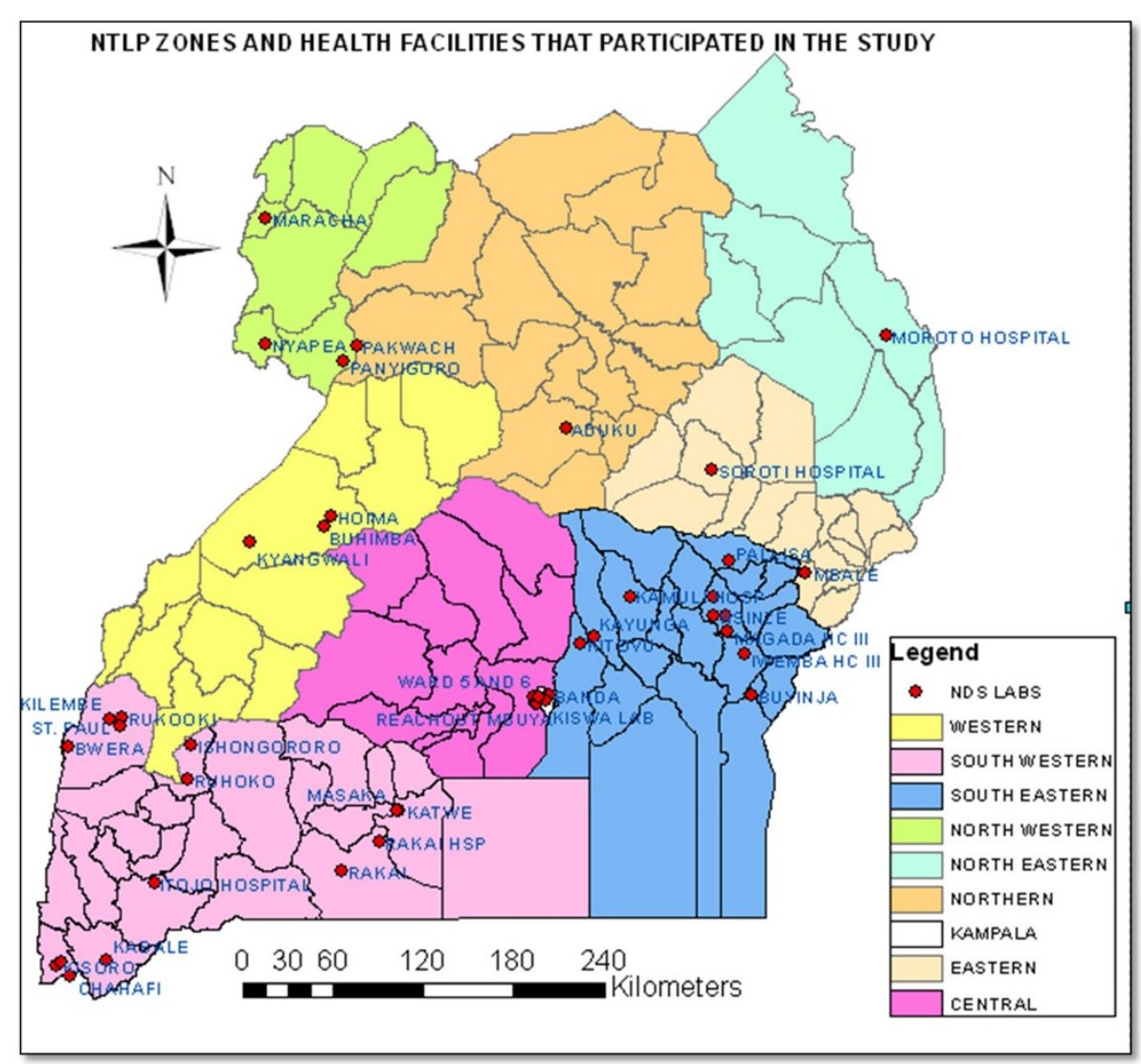

Figure 1 Map of Uganda showing health facilities which participated in the study and the NTLP zones.

were thawed overnight at $-20^{\circ} \mathrm{C}$ and later at room temperature for 12 hours. The vials were centrifuged at 15,000 $\mathrm{g}$ for $30 \mathrm{~min}$ and the pellet was washed twice with $500 \mathrm{ul}$ of Qiagen PCR water. The final pellet was resuspended in $100 \mu \mathrm{l}$ of Qiagen PCR-water, heated at $95^{\circ} \mathrm{C}$ for 30 minutes to kill and lyse the bacilli and later sonicated for $15 \mathrm{~min}$ at room temperature. The extracted crude genomic DNA in the supernatant was recovered by centrifugation at $15,000 \mathrm{~g}$ for $30 \mathrm{~min}$; the latter was used immediately in the real time PCR (RT-PCR) assay or stored at $-20^{\circ} \mathrm{C}$ for future use.

\section{SNP typing of Mycobacterium tuberculosis}

A SNP (Rv0040c-0619n) identifying the Uganda II (MTB) with its accompanying designed primers and probes as previously described [18] was used in a real-time PCR [(RT)PCR] SNP assay. The (RT)PCR analysis involved 2 steps. The first was amplification $\left(40\right.$ cycles of $95^{\circ} \mathrm{C}$ for $10 \mathrm{sec}, 57^{\circ} \mathrm{C}$ for $10 \mathrm{sec}$ and $72^{\circ} \mathrm{C}$ for $10 \mathrm{sec}$ of the target region(s)) to generate amplicons for the melting curve analysis. The results of melting curves were analyzed using LightCycler software version 1.5 to assign an isolate to a particular lineage depending on the melting temperature at which the hybridization probes dissociates from the amplicons. In all the assays we used MTB Uganda (MTB L4-U) genomic DNA from our laboratory, H37Rv genomic DNA (MTB lineage 4) and Central Asian strain (lineage 3) genomic DNA as control DNA.

\section{HIV testing}

HIV testing at all the 44 health care facilities followed the national algorithm using Unigold ${ }^{\ominus}$ (Trinity Biotech, Wiclock, Ireland) and Determine (Abbot, Tokyo, Japan) as the screening and confirmatory tests respectively. A third kit, Stat-Pak ${ }^{\circ}$ (Chethambutolio Medford NY, USA) was used when a mismatch between the confirmatory and the screening HIV test results on the same sample were reported. All participants were offered this test algorithm in accordance with the Uganda Ministry of Health guidelines.

\section{Data management and analysis}

Data on demographics, microscopy, culture and DST results was double entered in epi-info V6 (2000 CDC Atlanta GA USA), as part of the anti-TB drug resistance study, while results on molecular studies was entered in MS Excel. Analysis was done in Stata v10 (STATA Corp. College Station TX USA.) The Chi-square or the 2-sided 
Fisher's exact tests were used where appropriate for comparison of categorical variables. Univariate and multivariate analysis was done using logistic regression to identify variables associated with the T2/Uganda II MTB genotype. Contribution of the variables to the model was done using the likelihood ratio Chi square test. All significance testing was at the $95 \%$ confidence level.

Our primary outcome was the proportion of MTB patients with the Uganda II family calculated as a proportion across all clusters after weighing for the exact sampling probabilities for each new individual patient for whom DST results were available. Associations with MDR, HIV infection, patient age, previous history of TB treatment and urban or rural residence were also studied. In all these calculations, confidence intervals and pvalues were adjusted for cluster design by first order Taylor linearization and by second order correlation of Rao and Scott of the Pearson $X^{2}$ respectively as implemented by Stata svy commands [25].

\section{Ethical approval and consent procedure}

Ethical and scientific approval of the study was granted by Makerere University College of Health Sciences, Faculty of Medicine review board and the Uganda National Council of Science and technology. All adult participants gave written informed consent before participation. Additionally, we obtained written informed consent from the parent/guardian of participants under the age of 18 years. The consent process included storage and use of the collected sputum samples for further studies.

\section{Results}

Out of the 1537 patients included in the survey, 127 were culture negative, 77 samples were contaminated, eight samples grew non-tuberculous mycobacteria, and 1325 samples grew MTB based on IS6110-PCR analysis. Of these 1325 isolates, 324 did not grow on subculture (done for molecular analysis), leaving 1001 available for genotyping. Twenty-eight of these were excluded from further analysis due to inconclusive genotyping results. Thus, results on MTB genotype were available for single isolates of 973 patients. Of these isolates, 630 (64.8\%) belonged to male participants. Mean age of participants was 34.7 years, $25-34$ years being the modal age group $(n=330 ; 34.3 \%)$. Out of the eight zones that participated in this study, south west zone contributed the highest number of isolates $(\mathrm{n}=313 ; 32.0 \%)$. Of the 973 patients, 297 (30.5\%) tested positive for HIV, 217 (22.3\%) of whom had already tested HIV positive before enrolment. Previously treated TB patients contributed 78 (8.1\%) of the isolates. Generally there was no difference with regard to demographic characteristics (with exception of the zone where the patient was enrolled) of the patients included in the survey between those whose isolates were included and those whose were not included in the molecular typing (Table 1).

Of the 973 MTB isolates analysed with valid results, 422 (43.4\%) were of the Uganda II family. Among the eight NTLP zones that participated in this survey, south west zone had the highest proportion of this genotype, 172/313 (55.0\%; 95\% CI, 49.2-60.5), while south east had the lowest 7/35 (19.4\%; 95\% CI 8.1-36.0). We found the Uganda II family less distributed in the east and south east zones as compared to the south west zone $(\mathrm{p}<0.001)$ (Table 2). The 25-34 year age group had the highest proportion of the Uganda II family $(48.2 \%)$ although there was no statistical significance of the differences in distribution of this genotype among the different age groups. We found no association between the Uganda II family distribution with previous history of TB treatment and rural/urban residence.

On multivariable analysis, isolates belonging to other genotypes other than the Uganda II family were more likely to have resistance to any of the first-line drugs $\left(\mathrm{OR}^{\text {adj }} 2.9\right.$; 95\% CI, 1.63-5.06; $\mathrm{p}=0.001$ ) and more likely to be MDR $\left(\mathrm{OR}^{\text {adj }} 4.9 ; 95 \% \mathrm{CI}, 1.15-20.60 ; \mathrm{p}=0.032\right)$ than the Uganda II family, even though MDR isolates were few $(n=23)$. Included in our model for adjustment were the NTLP zone where the patient was enrolled, patient category (new or previously treated), age group, and participant residence (rural/urban) (Table 3). In NTLP zones where the Uganda II family was less distributed, participants had an increased risk of up almost twice $\left(\mathrm{OR}^{\text {adj }} 1.8\right.$; $95 \% \mathrm{CI}, 1.25-2.62$; $\mathrm{p}=$ 0.001) of having drug resistance as compared to south west zone where this genotype contributed a larger proportion to the sample (Table 4). No association between HIV infection and the Uganda II family (OR 1.09; 95\% CI, 0.731.63; $\mathrm{p}=0.648$ ) was established at univariable analysis.

\section{Discussion}

In this cross-sectional molecular analysis of $M$. tuberculosis strains circulating in Uganda, we clearly demonstrate the Uganda II family as the major cause of morbidity due to TB in the country although at different levels of predominance in the eight NTLP (i.e. geographic) zones. Its frequency was highest in the south west and lowest in the south east zone (see Figure 1). Our study showed that this genotype is less likely to develop resistance to any of the anti-TB drugs compared to all the other genotypes taken as a single group, but no association with HIV infection was demonstrated.

We found the Uganda II family about 2.9 times less likely to be resistant to any of the first-line anti-TB drugs and almost 5 times less likely to be MDR as compared to the non Uganda II MTB family. It confirms our observation from a similar survey done in Kampala where the T2 Uganda genotype strains were less likely to be drug resistant compared to other, geographically more diverse genotypes such LAM, CAS and T1 [22]. That the Uganda II 
Table 1 Characteristics of patients enrolled in the study

\begin{tabular}{|c|c|c|c|c|c|}
\hline Characteristic & & $\begin{array}{l}\text { Enrolled in survey } \\
\mathrm{N}=1537 \mathrm{n}(\%)\end{array}$ & $\begin{array}{l}\text { Included for molecular } \\
\text { analysis N = 973 n (\%) }\end{array}$ & $\begin{array}{l}\text { Not included for molecular } \\
\text { analysis } N=564 n(\%)\end{array}$ & $\mathrm{p}$-value \\
\hline \multirow[t]{2}{*}{ Sex } & Male & $1018(66.2)$ & $630(64.7)$ & $388(68.8)$ & 0.106 \\
\hline & Female & $519(33.8)$ & $343(35.3)$ & $176(31.2)$ & \\
\hline \multirow[t]{6}{*}{ Age } & 13-14 & $33(2.2)$ & $21(2.2)$ & $12(2.1)$ & 0.956 \\
\hline & $15-24$ & $299(19.5)$ & $189(19.8)$ & 108(19.2) & \\
\hline & $25-34$ & $521(33.4)$ & $330(34.3)$ & $191(34.0)$ & \\
\hline & $35-44$ & $366(23.8)$ & $235(24.5)$ & $131(23.3)$ & \\
\hline & $45-54$ & $167(10.9)$ & $100(10.4)$ & $67(11.9)$ & \\
\hline & $>55$ & $139(9.0)$ & $86(9.0)$ & $53(9.43)$ & \\
\hline \multirow[t]{3}{*}{ HIV already diagnosed positive } & Yes & $339(22.1)$ & $217(22.3)$ & $122(21.6)$ & 0.586 \\
\hline & No & $873(53.6)$ & $527(54.2)$ & $296(52.5)$ & \\
\hline & Unknown & $375(24.4)$ & $229(23.5)$ & $146(25.9)$ & \\
\hline \multirow[t]{8}{*}{ TB control Zone } & South West & $482(31.4)$ & $278(28.6)$ & $204(36.2)$ & 0.004 \\
\hline & Kampala & $457(29.7)$ & $313(31.2)$ & $144(25.5)$ & \\
\hline & South East & $97(6.3)$ & $59(6.1)$ & $38(6.7)$ & \\
\hline & Eastern & $53(3.5)$ & $28(2.9)$ & $25(4.4)$ & \\
\hline & North East & $152(9.9)$ & $89(9.2)$ & $63(11.2)$ & \\
\hline & North & $52(3.4)$ & $36(3.7)$ & $16(2.8)$ & \\
\hline & North West & $149(9.7)$ & $104(10.7)$ & $45(8.0)$ & \\
\hline & Western & $95(6.2)$ & $66(6.8)$ & $29(5.1)$ & \\
\hline \multirow[t]{3}{*}{ HIV results at (re)testing } & Positive & $469(30.5)$ & $297(30.5)$ & $172(30.5)$ & 0.216 \\
\hline & Negative & $1054(68.6)$ & $664(68.2)$ & $390(69.2)$ & \\
\hline & Missing & $14(0.91)$ & $12(1.23)$ & $2(0.35)$ & \\
\hline \multirow[t]{2}{*}{ Previous TB treatment } & Yes & $140(9.2)$ & $78(8.1)$ & $62(11.3)$ & 0.057 \\
\hline & No & $1397(90.8)$ & $883(91.9)$ & $500(89.0)$ & \\
\hline
\end{tabular}

family is negatively associated with M/DR-TB is further supported by the higher levels M/DR-TB in zones where this genotype is less prevalent such as the east zone. Here the prevalence of drug resistance was up to almost 2 times higher than in the south west zone where the majority of the isolates belonged to the Uganda II family after adjusting for patients' HIV status, treatment category, rural or urban residence and sex (Table 4). The negative association reported in our earlier analysis [22] between the T2 Uganda genotype and any drug resistance is thus confirmed in this study, and also exists for MDR (stronger than even the association with any resistance), possibly due to larger numbers of MDR-TB patients to establish a statistically significant difference.

Contrary to our findings, in some high burden TB settings the predominant MTB genotype has been associated with M/DR. The Beijing genotype in particular has been documented to cause outbreaks of MDR-TB where this strain is the major cause of TB morbidity [26]. It remains a subject for further analysis whether the Uganda II family is inherently less likely to become drugresistant (i.e. has a lower potential for acquiring drug resistance), or that drug-resistant Uganda II family strains are less easily transmitted than other drugresistant strains. The latter could occur if for example (multi)drug-resistant Uganda II strains cause clinical infections with lower bacterial load, or show higher cure rates with first-line treatment, than do (multi)drug-resistant strains of other genotypes. This could reflect differences in adaptation to the Ugandan host population between the more indigenous Uganda II family strains and more recently imported strains such as LAM, CAS and $\mathrm{T} 1$. In addition, one could speculate that predominance of the Uganda II family plays a causative role with regard to reported low levels anti-TB drug resistance in Uganda [5], and that similar genotypic differences in association with drug resistance exist elsewhere in subSaharan Africa where low levels of (M)DR-TB have been reported.

Despite a high TB/HIV co-infection rate in our sample (30.2\%) we found no association between HIV infection and Uganda II strains similar to findings of related studies elsewhere in SSA [27]. This finding suggests that the predominance of the Uganda II strains is unlikely to be 
Table 2 Analysis of risk factors associated with Uganda II family among sputum smear-positive TB patients in Uganda

\begin{tabular}{|c|c|c|c|c|}
\hline \multirow[t]{2}{*}{ Risk Factor } & & \multirow[t]{2}{*}{ Proportion n/N (\%) N=961 } & \multicolumn{2}{|c|}{ ** Univariate analysis } \\
\hline & & & OR $(95 \% \mathrm{Cl})$ & p-value \\
\hline \multirow[t]{2}{*}{ Sex } & Male & $279 / 630(44.3)$ & $1.12(0.83-1.52)$ & 0.420 \\
\hline & Female & $143 / 343(41.7)$ & Ref. & \\
\hline \multirow[t]{6}{*}{ Age } & $15-24$ & 71/189 (37.6) & Ref. & \\
\hline & $13-14$ & 10/21 (47.6) & $0.66(0.25-1.72)$ & 0.386 \\
\hline & $25-34$ & 159/330 (48.2) & $0.65(0.45-9.20)$ & 0.017 \\
\hline & $35-44$ & $96 / 235(40.9)$ & $0.87(0.62-1.21)$ & 0.406 \\
\hline & $45-54$ & $45 / 100(45.0)$ & $0.74(0.46-1.19)$ & 0.210 \\
\hline & $>55$ & $35 / 86(40.7)$ & $0.87(0.47-1.60)$ & 0.660 \\
\hline \multirow[t]{8}{*}{ Zone } & South West & $172 / 313(55.0)$ & Ref. & \\
\hline & Kampala & 112/278(40.3) & $0.55(0.36-0.83)$ & 0.006 \\
\hline & Eastern & $22 / 89(24.7)$ & $0.26(0.17-0.41)$ & $<0.001$ \\
\hline & South East & $7 / 36(19.40)$ & $0.20(0.14-0.28)$ & $<0.001$ \\
\hline & North East & $26 / 59(44.1)$ & $0.64(0.35-1.17)$ & 0.146 \\
\hline & North & $10 / 28(35.7)$ & $0.45(0.31-0.64)$ & $<0.001$ \\
\hline & North West & 20/66 (30.3) & $0.32(0.18-0.55)$ & $<0.001$ \\
\hline & Western & $53 / 104(51.0)$ & $0.86(0.43-1.72)$ & 0.667 \\
\hline Previously treated for TB & Yes & $31 / 78(39.7)$ & $0.85(0.58-1.25)$ & 0.403 \\
\hline HIV status & Positive & 130/442 (29.4) & $1.09(0.73-1.63)$ & 0.648 \\
\hline Diagnosis made in an urban setting & Yes & 267/585 (45.6) & $0.80(0.49-1.32)$ & 0.385 \\
\hline
\end{tabular}

** Odds ratios and confidence intervals adjusted for cluster design.

due to changes in immunological pressure on the circulating MTB population as a result of the HIV epidemic.

Since we observed significant geographical variations with respect to the distribution of the Uganda II family, it can be speculated that the north east and south east zones where this genotype is less distributed might have a diversity of MTB strains that are imported through cross-border movement with neighbouring countries such as Kenya, Tanzania and beyond. Indeed the eastern border of Uganda acts as the entry/exit (Busia and Malaba) for goods and people from Mombasa port and the northern part of Kenya and, the Kilimanjaro region in Tanzania, while Kampala being the capital city is the major business centre and a pathway for people entering and exiting Uganda from all over the world. Human traffic at these entry/exit points might enhance transmission of communicable diseases, including $\mathrm{TB}$, with higher probability of strain diversity than in the south west zone. The other possibility could be that the Uganda II family might be genetically more adapted to indigenous human populations of the south west than the east and south east zones. Both hypotheses can only be confirmed through further research.

\section{Limitations}

Our study had limitations. We did not fully characterise the non-Uganda II family into specific lineages that have been previously documented as significantly contributing to the TB burden in this setting. Therefore we could not fully conclude which particular strain drives drug resistance in this locality and any associated factors such as transmissibility and potential to develop drug resistance

Table 3 Multivariate analysis of Uganda II family and anti-TB drug resistance among sputum smear-positive TB patients in Uganda

\begin{tabular}{|c|c|c|c|c|c|c|c|c|}
\hline \multirow[t]{3}{*}{ Genotype } & \multicolumn{8}{|c|}{ Resistance Pattern } \\
\hline & \multicolumn{4}{|c|}{ Any resistance } & \multicolumn{4}{|l|}{ MDR } \\
\hline & Proportion & $* *$ OR & $95 \% \mathrm{Cl}$ & p-value & Proportion & ${ }^{* *} \mathrm{OR}$ & $95 \% \mathrm{Cl}$ & p-value \\
\hline Uganda II & $26 / 422(6.2)$ & Ref. & & & $3 / 422(0.7)$ & Ref. & & \\
\hline Other & $91 / 549$ (16.6) & 2.9 & $1.63-5.06$ & 0.001 & $19 / 530(3.5)$ & 4.9 & $1.15-20.60$ & 0.032 \\
\hline
\end{tabular}

Others included in the model were National TB/Leprosy Program (NTLP) zone, patient category (new or previously treated), HIV status, age group, and residence (rural/urban).

** Odds ratios adjusted for cluster design. 
Table 4 Multivariable analysis of 'any resistance' and 'NTLP zone' in relation to the proportion of the Uganda II family among the sputum-smear positive TB patients in Uganda

\begin{tabular}{|c|c|c|c|c|c|c|}
\hline \multirow[b]{2}{*}{ Zone } & \multirow[t]{2}{*}{ Total number of isolates $\mathrm{N}=973$} & \multirow[t]{2}{*}{ Proportion of T2 isolates $n(\%)$} & \multicolumn{2}{|c|}{ Univariate analysis } & \multicolumn{2}{|c|}{ Multivariable analysis } \\
\hline & & & $* *$ OR $(95 \% \mathrm{Cl})$ & $\overline{p \text {-value }}$ & OR $(95 \% \mathrm{Cl})$ & ${ }^{*}$ p-value \\
\hline South West & 313 & $172(55.0)$ & Ref. & & Ref. & \\
\hline Kampala & 278 & $112(40.3)$ & $1.9(1.34-2.79)$ & 0.004 & $1.8(1.23-2.53)$ & 0.005 \\
\hline Eastern & 89 & $22(23.6)$ & $1.9(0.76-4.79)$ & 1.57 & $1.9(0.8-4.43)$ & 0.122 \\
\hline South East & 36 & $7(19.4)$ & $1.7(1.26-2.35)$ & 0.001 & $1.8(1.25-2.62)$ & 0.003 \\
\hline North East & 59 & $28(44.1)$ & $1.9(1.27-2.73)$ & 0.030 & $1.8(1.23-2.53)$ & 0.001 \\
\hline North & 28 & $10(35.7)$ & $0.8(0.58-1.08)$ & 0.137 & $1.0(0.69-1.45)$ & 0.980 \\
\hline North West & 66 & $20(30.3)$ & $0.5(0.27-1.10)$ & 0.295 & $0.73(2.05-2.78)$ & 0.113 \\
\hline Western & 104 & $53(51.0)$ & $1.5(0.22-1.61)$ & 0.134 & $1.6(0.89-2.78)$ & 0.546 \\
\hline
\end{tabular}

** Odds ratios confidence intervals and p-values adjusted for cluster design.

* $=\mathrm{P}$ value for the difference in resistance between the south western zone and each of the other zones included in the study.

Other variables included in the model are patient category, sex, residence (rural/urban), HIV status.

Ref $=$ reference category.

as documented elsewhere. However our aim was to find out the role of the predominant genotype in the observed low levels of anti-TB drug resistance in this locality and our earlier report [22], though limited in terms of geographical coverage, fully characterised the less predominant MTB lineages in relation M/DR-TB and HIV infection. We however strongly recommend a more in depth analysis to characterize the 'non- Uganda II family' and its distribution throughout Uganda. Secondly, we employed a typing method (identification of genotypespecific SNPs) that was different from the method that was used for the Kampala survey (spoligotyping) in which the negative association of the T2 Uganda genotype with drug resistance was initially observed. However, earlier studies have shown that the T2 genotype and the Uganda II genotype strongly overlap [18]. Thirdly, only sputum smear-positive TB patients were included in the study since this was an extension of a drug resistance survey. This sampling frame could limit generalizability of our results to smear negatives should there be a difference in the distribution of the Uganda II family strains. Since differences in bacterial load and resulting transmission fitness of drug resistant strains may in part explain the observed association, it would be interesting to extend the current study with sputum smear-negative patients.

Few MDR patients were available to provide enough power for analysis of associations between the Uganda II family and MDR although we managed to demonstrate this with wide confidence interval.

\section{Conclusion}

This study shows the Uganda II family to be the predominant MTB genotype in Uganda and confirms earlier findings that this genotype is less likely to be drug resistant compared to other genotypes combined. This may in part explain the low levels of drug resistance found in Uganda. Similar negative associations between the predominant indigenous MTB strains and drug resistance may exist elsewhere in SSA [28].

\section{Competing interests}

The authors declare that they have no competing interests.

\section{Authors' contribution}

$N E, D L, M L J$ and FGJC conceived the idea. MLJ, FGJC, NE, KM, EMW, DL and GWK designed and performed the experiments. EMW, NE and MLJ designed the primers and probes used in the study, analyzed and interpreted the genotyping data. DL and FGJC analyzed and interpreted the statistical data. MLJ, NE and FGJC contributed reagents, materials, and analysis tools. DL, FGJC, EMW, MLJ, NE and DPK wrote the manuscript. DPK proofread the final version of the manuscript and handled the submission and review process. All authors read and approved the final manuscript.

\section{Acknowledgement}

We are grateful to the staff of the Medical and Molecular Laboratories (Makerere University College of Health Sciences) and the National TB Reference Laboratory (Uganda) for processing samples sputum samples and the TB patients whose samples were collected to make this study possible.

\section{Funding}

There was no specific funding for this study, however, the corresponding author and the Molecular Biology Laboratory where the molecular assays were conducted have been supported by the National Institute of Allergy and infectious Diseases (grant \#s R03 Al062849 and R01 Al075637; and contract \#s NO1-AI-95383 \& HHSN266200700022C/NO1-Al-70022 (Tuberculosis research unit [TBRU], respectively). The funders had no role in study design, data collection and analysis, decision to publish, or preparation of the manuscript.

\section{Author details}

${ }^{1}$ National Tuberculosis and Leprosy Program, Kampala, Uganda. ${ }^{2}$ National Tuberculosis Reference Laboratory (NTRL), Kampala, Uganda. ${ }^{3}$ Department of Medical Microbiology, Makerere University College of Health Sciences, Kampala, Uganda. ${ }^{4}$ Department of Global health and Amsterdam Institute for Global Heath and Development, Academic Medical Center, Amsterdam, The Netherlands KNCV Tuberculosis Foundation, The Hague, The Netherlands. ${ }^{5}$ Department of Bio-molecular Resources and Biolab Sciences, College of Veterinary Medicine, Animal Resources and Bio Security, Makerere University, Kampala, Uganda.

Received: 17 July 2014 Accepted: 11 December 2014

Published online: 19 December 2014 


\section{References}

1. Lauzardo M, Ashkin D: Phthisiology at the dawn of the new century. Chest 2000, 117(5):1455-73.

2. Affolabi D, Adjagba OABG, Tanimomo-Kledjo B, Gninafon M, Anagonou SY, Portaels F: Anti-tuberculosis drug resistance among new and previously treated pulmonary tuberculosis patients in Cotonou, Benin. Int J Tuberc Lung Dis Off J Int Union Tuberc Lung Dis 2007, 11(11):1221-4.

3. Suchindran S, Brouwer ES, Van Rie A: Is HIV infection a risk factor for multidrug resistant tuberculosis? A systematic review. PLoS One 2009, 4(5):e5561.

4. Kuaban C, Bercion R, Jifon G, Cunin P, Blackett KN: Acquired anti-tuberculosis drug resistance in Yaounde, Cameroon. Int J Tuberc Lung Dis Off J Int Union Tuberc Lung Dis 2000, 4(5):427-32.

5. Lukoye D, Adatu F, Musisi K, Kasule GW, Were W, Odeke R, Kalamy JN, Awor A, Date Anand J: Date Anand, Joloba. Anti-tuberculosis drug resistance among new and previously treated sputum smear-positive tuberculosis patients in Uganda: results of the first national survey. PLoS One 2013, 8 (8):e70763.

6. Demissie M, Lemma E, Gebeyehu M, Lindtjorn B: Sensitivity to anti-tuberculosis drugs in HIV-positive and -negative patients in Addis Ababa. Scand J Infect Dis 2001, 33(12):914-9.

7. Yimer SA, Agonafir M, Derese Y, Sani Y, Bjune GA, Holm-Hansen C: Primary drug resistance to anti-tuberculosis drugs in major towns of Amhara region, Ethiopia. APMIS Acta Pathol Microbiol Immunol Scand 2012, 120(6):503-9.

8. Van Halsema CL, Fielding KL, Chihota VN, Lewis JJ, Churchyard GJ, Grant AD: Trends in drug-resistant tuberculosis in a gold-mining workforce in South Africa, 2002-2008. Int J Tuberc Lung Dis Off J Int Union Tuberc Lung Dis 2012, 16(7):967-73.

9. Sanchez-Padilla E, Dlamini T, Ascorra A, Rüsch-Gerdes S, Tefera ZD, Calain P, de la Tour R, Jochims F, Richter E, Bonnet M: High prevalence of multidrug-resistant tuberculosis, Swaziland, 2009-2010. Emerg Infect Dis 2012, 18(1):29-37.

10. Espinal MA, Laszlo A, Simonsen L, Boulahbal F, Kim SJ, Reniero A, Hoffner S, Rieder HL, Binkin N, Dye C, Williams R, Raviglione MC: Global trends in resistance to antituberculosis drugs. World Health Organization-International Union against tuberculosis and lung disease working group on antituberculosis drug resistance surveillance. N Engl J Med 2001, 344(17):1294-303.

11. World Health Organization: Global tuberculosis control: WHO report 2011. Geneva: World Health Organization; 2011.

12. Puustinen K, Marjamäki M, Rastogi N, Sola C, Filliol I, Ruutu P, Holmström P, Viljanen Matti K. Soini H: Characterization of Finnish Mycobacterium tuberculosis isolates by spoligotyping. J Clin Microbiol 2003, 41(4):1525-8.

13. Van Crevel $R$, Nelwan $R H$, de Lenne $W$, Veeraragu $Y$, van der Zanden $A G$, Amin Z, van der Meer JW, van Soolingen D: Mycobacterium tuberculosis Beijing genotype strains associated with febrile response to treatment. Emerg Infect Dis 2001, 7(5):880-3.

14. Mostowy S, Cousins D, Brinkman J, Aranaz A, Behr MA: Genomic deletions suggest a phylogeny for the Mycobacterium tuberculosis complex. $J$ Infect Dis 2002, 186(1):74-80.

15. Kremer K, van Soolingen D, Frothingham R, Haas WH, Hermans PW, Martín $C$, et al: Comparison of methods based on different molecular epidemiological markers for typing of Mycobacterium tuberculosis complex strains: interlaboratory study of discriminatory power and reproducibility. J Clin Microbiol 1999, 37(8):2607-18.

16. Wampande EM, Mupere E, Debanne SM, Asiimwe BB, Nsereko M, Mayanja H, Eisnack K, Kaplan G, Boom H, Gagneux S, Joloba M: Long-term dominance of Mycobacterium tuberculosis Uganda family in peri-urban Kampala-Uganda is not associated with cavitary disease. BMC Infect Dis 2013, 13:484.

17. Jagielski T, van Ingen J, Rastogi N, Dziadek J, Mazur PK, Bielecki J: Current methods in the molecular typing of Mycobacterium tuberculosis and other mycobacteria. BioMed Res Int 2014, 2014:645802.

18. Gagneux S, DeRiemer K, Van T, Kato-Maeda M, de Jong BC, Narayanan S, Nicol M, Niemann S, Kremer K, Gutierrez M, Hilty M, Hopewell P, Small P: Variable hostpathogen compatibility in Mycobacterium tuberculosis. Proc Natl Acad Sci U S A 2006, 103(8):2869-73.

19. Asiimwe BB, Ghebremichael S, Kallenius G, Koivula T, Joloba ML: Mycobacterium tuberculosis spoligotypes and drug susceptibility pattern of isolates from tuberculosis patients in peri-urban Kampala, Uganda. BMC Infect Dis 2008, 8:101.
20. Niemann S, Rüsch-Gerdes S, Joloba ML, Whalen CC, Guwatudde D, Ellner JJ, Eisenack K, Fumokong N, Johnson JL, Aisu T, Mugerwa R.D, Okwera A, Schwander SK: Mycobacterium africanum subtype II is associated with two distinct genotypes and is a major cause of human tuberculosis in Kampala, Uganda. J Clin Microbiol 2002, 40(9):3398-405.

21. Nabyonga L, Kateete DP, Katabazi FA, Odong PR, Whalen CC, Dickman KR, Joloba M: Determination of circulating Mycobacterium tuberculosis strains and transmission patterns among pulmonary TB patients in Kawempe municipality, Uganda, using MIRU-VNTR. BMC Res Notes 2011, 4:280.

22. Lukoye D, Katabazi FA, Musisi K, Kateete DP, Asiimwe BB, Okee M Joloba M, Cobelens F. The T2 Mycobacterium tuberculosis Genotype, Predominant in Kampala-Uganda, Shows Negative Correlation with anti-Tuberculosis Drug Resistance. Antimicrob. Agents Chemother. doi:10.1128/AAC.02338-13.

23. Van Embden JD, Cave MD, Crawford JT, Dale JW, Eisenach KD, Gicquel B, Martin C, McAdam R, Shinnick TM, Small P. Strain identification of Mycobacterium tuberculosis by DNA fingerprinting: recommendations for a standardized methodology. J Clin Microbiol 1993, 31(2):406-9.

24. WHO/IUATLD Global Project on Anti-tuberculosis Drug Resistance Surveillance: Guidelines for surveillance of drug resistance in tuberculosis [Internet]. Geneva: World Health Organization; 2009. [cited 2014 Jun 5]. Available from: http:// whqlibdoc.who.int/publications/2009/9789241598675_eng.pdf.

25. Rao JNSA: A simple method for the analysis of clustered binary data. Biometrics 1992, 48(2):577-85.

26. De Steenwinkel JEM, ten Kate MT, de Knegt GJ, Kremer K, Aarnoutse RE, Boeree MJ, Verbrugh $H$, van Soolingen D, Bakker W: Drug susceptibility of Mycobacterium tuberculosis Beijing genotype and association with MDR TB. Emerg Infect Dis 2012, 18(4):660-3.

27. Middelkoop K, Bekker L-G, Mathema B, Shashkina E, Kurepina N, Whitelaw A, Fallows D, Morrow C, Kreiswirth KG, Wood R: Molecular epidemiology of Mycobacterium tuberculosis in a South African community with high HIV prevalence. J Infect Dis 2009, 200(8):1207-11.

28. Hermans PW, Messadi F, Guebrexabher H, van Soolingen D, de Haas PE, Heersma H, de Neeling H, Ayoub A, Portaels F, Frommel F: Analysis of the population structure of Mycobacterium tuberculosis in Ethiopia, Tunisia, and The Netherlands: usefulness of DNA typing for global tuberculosis epidemiology. J Infect Dis 1995, 171(6):1504-13.

\section{Submit your next manuscript to BioMed Central and take full advantage of:}

- Convenient online submission

- Thorough peer review

- No space constraints or color figure charges

- Immediate publication on acceptance

- Inclusion in PubMed, CAS, Scopus and Google Scholar

- Research which is freely available for redistribution 